\title{
After-effects of exercise on haemodynamics and muscle sympathetic nerve activity in young patients with dilated cardiomyopathy
}

\author{
Kazuhiro Hara, John S Floras
}

\begin{abstract}
Objective-To determine the after-effects on sympathetic nerve activity and calf and systemic haemodynamics of symptom-limited exercise in young patients with dilated cardiomyopathy.

Patients-14 young patients with dilated cardiomyopathy (mean (SEM) age 35 (2) yr) and 17 healthy controls (age 29 (2) yr). Methods-Blood pressure, muscle sympathetic nerve activity, calf blood flow, plasma noradrenaline, and stroke volume were recorded during baseline rest and an hour after symptom-limited treadmill exercise (up to $45 \mathrm{~min}$ ) at $70 \%$ of resting heart rate reserve.
\end{abstract}

Results-Before exercise, sympathetic nerve activity (45 (6) $v 21$ (2) bursts. min $^{-1}$; $\mathbf{P}=0.001)$ and calf vascular resistance (55 (5) $v 31$ (3) units; $P<0.0005$ ) were higher in the dilated cardiomyopathy group, and there was a significant correlation between these two variables $(r=$ +0.64; $P<0.001)$. Patients with ventricular dysfunction exercised for 31 (3) $\mathrm{min}$. In both groups there were significant and similar reductions in diastolic blood pressure, total peripheral resistance, and calf vascular resistance after exercise. Sympathetic nerve activity and plasma noradrenaline were unchanged and there was no longer any relation between muscle sympathetic nerve activity and calf vascular resistance. Cardiac output increased in both groups but, in contrast to healthy controls, mean values for systolic blood pressure and stroke volume $(P<0.005)$ did not decrease in the cardiomyopathy group. For similar reductions in total peripheral resistance, there were two to three fold greater increases in stroke volume after exercise in patients with left ventricular dysfunction $(P<0.03)$. There was no relation between exercise duration and the magnitude of these after-effects of exercise in these patients.

Conclusions-In young patients with dilated cardiomyopathy the haemodynamic after-effects of submaximal symptom-limited exercise resemble responses to pharmacological afterload reduction but are not accompanied by reflex sympathetic activation. Sustained calf and systemic vasodilation after exercise were not attenuated, as compared with healthy controls. These cardiac, peripheral, and sympathoneural after-effects provide further support for exercise training as a non-pharmacological adjunct to the management of chronic stable heart failure.

(Heart 1996;75:602-608)

Keywords: exercise; heart failure; haemodynamics; sympathetic nervous system.

The potential benefits of exercise training for patients with heart failure are under active investigation. ${ }^{1-3}$ Most studies of the acute effect of this intervention in patients with left ventricular dysfunction have focused on observations made during exercise. There is little documentation of regional and systemic haemodynamics and sympathetic activity during the recovery period after exercise, even though rapid changes in noradrenergic drive, regional blood flow, and loading conditions at this time may have adverse implications for the diseased myocardium.

In people with normal ventricular function, running or bicycle exercise is usually followed by vasodilatation in both the exercised and non-exercised muscle beds. ${ }^{4-6}$ Stroke volume falls, but this is offset by tachycardia, resulting in higher cardiac output after exercise. ${ }^{467}$ For reasons that are not clear, in some people peripheral resistance increases significantly above baseline values for an hour or more after exercise. $^{8-10}$ Those with left ventricular dysfunction should derive particular benefit if cardiac output increases and afterload decreases, whereas sustained increases in peripheral resistance could be detrimental, particularly if vasodilatation after exercise evokes reflex increases in efferent sympathetic nerve traffic to the heart, kidney, or skeletal muscle. ${ }^{11}$

Interestingly, in subjects with normal ventricular function post-exercise hypotension is not accompanied by any reflex increase in muscle sympathetic nerve activity, ${ }^{712}$ or plasma noradrenaline concentrations. ${ }^{57}$ Moreover, in men with borderline hypertension, who have increased noradrenergic drive, ${ }^{13}$ reductions in blood pressure after exercise are associated with decreases in sympathetic nerve traffic to muscle. ${ }^{12}$ To explain these observations we suggested that an acute bout of exercise could reset the arterial baroreceptor modulation of sympathetic outflow. ${ }^{714}$ It is not known whether exercise has similar sympathoinhibitory after-effects in heart failure, a condition of considerably greater nora-
Cardiology, Room 1615,

Mount Sinai Hospital, 600

University Avenue, Toronto

Accepted for publication

15 January 1996 
drenergic activation, ${ }^{11} 1516$ or whether recovery from exercise in such subjects is characterised by hypotension, and reflex increases in sympathetic traffic to muscle, and in peripheral vascular resistance. Our specific hypothesis in these experiments in young patients with dilated cardiomyopathy was that exercise would be followed by sustained reductions in blood pressure, sympathetic nerve activity, and resistance to blood flow in the calf-that is, the vascular bed distal to the recording electrode.

\section{Patients and methods \\ STUDY GROUPS}

We studied 14 patients (age 35 (2) yr, range 19-49; 7 men, 7 women), who were in stable condition, in sinus rhythm, with global hypokinesis, left ventricular ejection fraction $\leqslant 35 \%$, left ventricular end diastolic dimension $\geqslant 60$ $\mathrm{mm}$, normal coronary arteries, and no active myocarditis on endomyocardial biopsy. ${ }^{17}$ Patients were New York Heart Association class I $(n=5)$, II $(n=6)$, or III $(n=3)$. Dilated cardiomyopathy arose post partum in two and was idiopathic in 12. All were taking either captopril or enalapril: 12 were taking digitalis and eight diuretics. These drugs were withheld for $24 \mathrm{~h}$ or more, before study. We also studied 17 young untrained age-matched (29 (2); range 19-45 yr) healthy (non-medical and non-hospital) controls. None of the 31 subjects exercised regularly. All provided informed written consent as approved by our University Human Subjects Review Committee.

\section{PROTOCOL}

Preparation

Subjects avoided exercise $48 \mathrm{~h}$ before the study and alcohol, caffeine-containing beverages, and tobacco over the $12 \mathrm{~h}$ preceding the study.

Experiments were performed in the morning. There were three parts to each session:

\section{Pre-exercise}

Using $\mathbf{M}$ mode echocardiography, we determined left ventricular end diastolic and end systolic dimensions, mass index, fractional shortening, and aortic ring diameter (D) ${ }^{18-20}$ (table 1). An indwelling saline-lock catheter was introduced into a right arm antecubital vein. Blood pressure was measured by the oscillometric technique by an automatic cuff recorder (Physio Control Lifestat 200, Redwood, WA). Heart rate was derived from

Table 1 Characteristics of study groups

\begin{tabular}{lcc}
\hline & $\begin{array}{c}\text { Healthy } \\
\text { controls }\end{array}$ & $\begin{array}{l}\text { Dilated } \\
\text { cardiomyopathy }\end{array}$ \\
\hline Number & 17 & 14 \\
Sex (M/F) & $13 / 4$ & $7 / 7$ \\
Age (yr) & $29(2)$ & $35(2)$ \\
Weight (kg) & $76(3)$ & $72(4)$ \\
Body mass index (kg.m ${ }^{-2}$ ) & $25(1)$ & $25(1)$ \\
Left ventricle: & & $70(2)^{\star \star}$ \\
End diastolic dimension (mm) & $51(1)$ & $791(17)^{\star \star}$ \\
Mass index (g.m $\left.{ }^{-2}\right)$ & $106(5)$ & $191(\%)$ \\
Fractional shortening (\%) & $35(5)$ & $16(1)^{\star \star}$ \\
\hline Values are mean (SEM). ${ }^{\star \star P}<0.001 v$ healthy controls.
\end{tabular}

lead II of the electrocardiogram. Right calf blood flow (CBF; ml. $\mathrm{min}^{-1} .100 \mathrm{ml}$ of calf vol$u^{u m e^{-1}}$ ) was estimated by venous occlusion plethysmography timed to give four estimates of calf blood flow per minute. ${ }^{720}$ Postganglionic muscle sympathetic nerve activity was recorded from the left peroneal nerve and expressed as bursts. min $^{-1} .{ }^{21} 22$ In our laboratory, the mean inter-observer variability in the visual evaluation of the microneurographic record is $3.9 \%$ and the mean intra-observer variability is $4.5 \% .^{23}$

Twenty minutes of rest were followed by a 15 minute baseline (pre-exercise) period. Supine blood pressure was measured every minute and heart rate, the electrocardiogram, and the mean voltage neurogram were recorded continuously onto paper. Calf blood flow was measured over the last two minutes after which venous blood was withdrawn for plasma noradrenaline and atrial natriuretic factor determinations. ${ }^{22}$ Blood pressure and heart rate were then measured simultaneously with instantaneous flow velocity in the ascending aorta, using continuous wave Doppler. ${ }^{20}{ }^{24}$ These values are stable over the time period of these experimental sessions, in the absence of interventions, in both healthy individuals and those with heart failure ${ }^{24}$ and highly reproducible, under resting conditions, at intervals of a month or more. ${ }^{2024}$ Stroke volume was calculated as the product of the mean of ten or more time velocity integrals and the cross-sectional area of the aortic orifice (A) (A $=\pi \times$ $\left.[D / 2]^{2}\right)^{6724}$ and cardiac output from stroke volume and heart rate.

\section{Exercise}

Symptom-limited submaximal exercise was performed for up to $45 \mathrm{~min}$. The electrocardiogram was monitored continuously and blood pressure every $5 \mathrm{~min}$. Treadmill speed and grade were adjusted to maintain heart rates at $70 \%$ of resting heart rate (RHR) reserve, calculated as $0.7 \quad[(220-$ age $)$ - RHR] + RHR. ${ }^{79}$ This corresponds to about $60 \%$ of maximal oxygen uptake. ${ }^{25}$

\section{Post-exercise}

Subjects then lay supine. The strain gauge and venous occlusion cuffs were applied to the left leg. In a subgroup (12 cardiomyopathy, eight healthy controls) immediate post-exercise values for blood pressure, heart rate, and calf blood flow were measured concurrently. Muscle sympathetic nerve activity was then recorded from the opposite, or right, peroneal nerve and blood pressure, heart rate, electrocardiogram, and the neurogram were recorded continuously until $60 \mathrm{~min}$ after exercise. As in previous protocols ${ }^{6712}$ the last 5 min were averaged to represent late post-exercise values. Calf blood flow was measured over the last two minutes of this hour, venous blood was drawn, then stroke volume was determined along with the corresponding blood pressure and heart rate.

\section{DERIVED VALUES}

Calf vascular resistance was calculated as 
Table 2 Systemic haemodynamics and plasma noradrenaline concentrations before and an hour after exercise

\begin{tabular}{|c|c|c|c|c|}
\hline \multirow[b]{2}{*}{ Variable } & \multicolumn{2}{|c|}{ Healthy controls $(n=17)$} & \multicolumn{2}{|c|}{ Dilated cardiomyopathy $(n=14)$} \\
\hline & Before & After & Before & After \\
\hline Systolic blood pressure $(\mathrm{mm} \mathrm{Hg})$ & $114(2)$ & $110(2)^{\star}$ & $99(4) \ddagger$ & $98(4)$ \\
\hline Mean arterial pressure $(\mathrm{mm} \mathrm{Hg})$ & $79(2)$ & $76(2)^{\star \star}$ & $71(3) \dagger$ & $68(3)^{\star}$ \\
\hline Diastolic blood pressure (mm Hg) & $61(2)$ & $58(2)^{\star}$ & $57(3)$ & $54(3)^{\star}$ \\
\hline Heart rate $\left(\min ^{-1}\right)$ & $56(2)$ & $66(3)^{\star \star \star}$ & $78(5) \ddagger$ & $84(4)^{\star \star}$ \\
\hline Stroke index $\left(\mathrm{ml} \cdot \mathrm{min}^{-1} \cdot \mathrm{m}^{-2}\right)$ & $39 \cdot 6(2 \cdot 6)$ & $37 \cdot 5(3)^{\star \star \star}$ & $24 \cdot 8(2 \cdot 2) \ddagger$ & $26 \cdot 2(2 \cdot 0)$ \\
\hline Cardiac index $\left(1 \cdot \mathrm{min}^{-1} \cdot \mathrm{m}^{-2}\right)$ & $2 \cdot 17(0 \cdot 13)$ & $2 \cdot 41(0 \cdot 16)^{\star \star \star}$ & $1 \cdot 85(0 \cdot 12)$ & $2 \cdot 11(0 \cdot 10)^{\star}$ \\
\hline $\begin{array}{l}\text { Total peripheral resistance } \\
\left(\text { dyn.s. } \mathrm{cm}^{-5}\right)\end{array}$ & $1623(109)$ & $1444(176)^{\star \star \star}$ & $1781(141)$ & $1464(90)^{\star \star \star}$ \\
\hline Total peripheral conductance & & & & \\
\hline$\left(\mathrm{ml} \cdot \mathrm{min}^{-1} \cdot \mathrm{mmHg}^{-1}\right)$ & $52 \cdot 6(3 \cdot 2)$ & $61 \cdot 3(4 \cdot 5)^{\star \star \star}$ & $48 \cdot 7(3.9)$ & $57 \cdot 4(3 \cdot 6)^{\star \star \star}$ \\
\hline Plasma noradrenaline (nmol.1-1 $)$ & $1 \cdot 1(0 \cdot 1)$ & $1 \cdot 4(0 \cdot 2)$ & $1.8(0.5)$ & $1 \cdot 6(0 \cdot 5)$ \\
\hline Atrial natriuretic factor $\left(\mathrm{nmol}^{-1^{-1}}\right)$ & $8 \cdot 8(1 \cdot 0)$ & $6 \cdot 7(0 \cdot 6)^{\star \star \star}$ & $44 \cdot 3(6 \cdot 8) \ddagger$ & $38 \cdot 8(5 \cdot 9)$ \\
\hline
\end{tabular}

Values are mean $(\mathrm{SEM}) .{ }^{\star} \mathrm{P}<0.05 ;{ }^{\star} \mathrm{P}<0.01 ;{ }^{\star \star \star} \mathrm{P}<0.005$ for after $v$ before exercise comparisons within subject groups. $\dagger \mathrm{P}<0.05 ; \ddagger \mathrm{P}<0.005$ for comparisons between patients with dilated cardiomyopathy and healthy controls before exercise.

Table 3 Muscle sympathetic nerve activity and calf haemodynamics before and an hour after exercise

\begin{tabular}{|c|c|c|c|c|}
\hline \multirow[b]{2}{*}{ Variable } & \multicolumn{2}{|c|}{ Healthy controls $(n=14)$} & \multicolumn{2}{|c|}{ Dilated cardiomyopathy $(n=13)$} \\
\hline & Before & After & Before & After \\
\hline $\begin{array}{l}\text { Muscle sympathetic nerve activity } \\
\text { (bursts.min } \\
\text { Calf blood flow }\left(\mathrm{ml} \cdot \mathrm{min}^{-1} .100 \mathrm{ml}^{-1}\right) \\
\text { Mean arterial pressure }(\mathrm{mm} \mathrm{Hg}) \\
\text { Calf vascular resistance (units) } \\
\text { Calf vascular conductance (units } \times 10^{3} \text { ) }\end{array}$ & $\begin{array}{l}21(2) \\
2 \cdot 8(0 \cdot 2) \\
81(2) \\
31(3) \\
37(3)\end{array}$ & $\begin{array}{l}21(3) \\
4 \cdot 8(0 \cdot 5)^{\star \star \star} \\
75(2)^{\star \star} \\
19(2)^{\star \star \star} \\
63(8)^{\star \star}\end{array}$ & $\begin{array}{l}45(6) \mathrm{tt} \\
1 \cdot 5(0 \cdot 1) \mathrm{tt} \\
74(3) \dagger \\
55(5) \mathrm{tt} \\
20(2) \mathrm{tt}\end{array}$ & $\begin{array}{l}48(6) \\
2 \cdot 5(0 \cdot 3)^{\star \star \star} \\
69(3)^{\star} \\
34(4)^{\star} \\
36(4)^{\star \star \star}\end{array}$ \\
\hline
\end{tabular}

Values are mean $\left(\right.$ SEM). ${ }^{\star} P<0.05 ;{ }^{\star \star} \mathrm{P}<0.005 ;{ }^{\star \star \star} \mathrm{P} \leqslant 0.001$ for after $v$ before exercise comparisons within subject groups. $+\mathrm{P}<0.05 ; \mathrm{t}+\mathrm{P}<0.005$ for baseline pre-exercise comparisons between dilated cardiomyopathy and healthy controls.

mean arterial pressure (MAP: diastolic $+1 / 3$ pulse pressure) divided by the average of 4-6 measures of calf blood flow, and calf vascular conductance (expressed as units $\times 10^{3}$ ) as the inverse of resistance. Total peripheral resistance (TPR) was calculated from: TPR (dyn.s. $\left.\mathrm{cm}^{-5}\right)=80(\mathrm{MAP} \mathrm{mm} \mathrm{Hg}) / \mathrm{CO}$ $\left(1 . \mathrm{min}^{-1}\right)$. Its inverse, total peripheral conductance, was expressed as $\mathrm{ml} . \mathrm{min}^{-1} \cdot \mathrm{mm} \mathrm{Hg}^{-1}$. Conductance units are preferred for the interpretation of changes in vascular tone when flow changes more than pressure. ${ }^{26}$
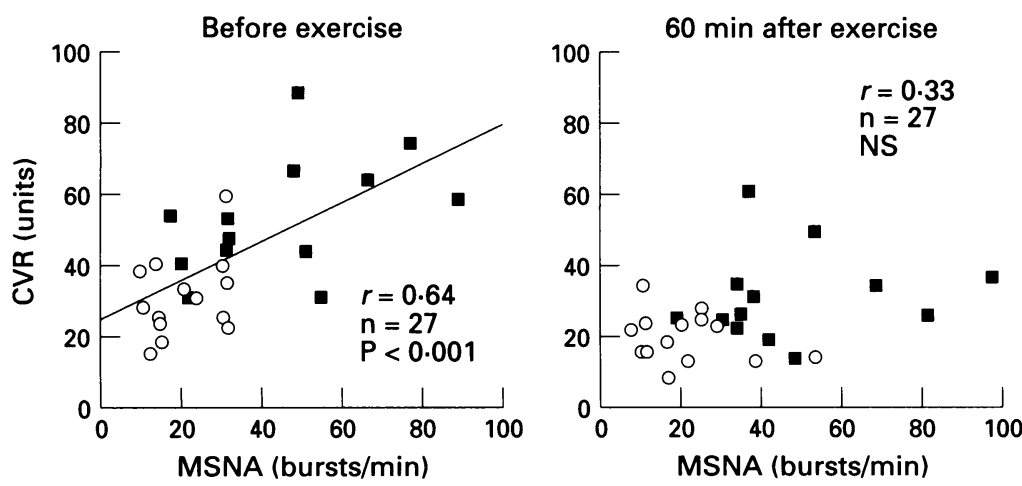

$\circ$ Healthy controls

- Dilated cardiomyopathy

Figure 1 Plots of muscle sympathetic nerve activity (MSNA) and calf vascular resistance (CVR) for all patients and controls. At rest before exercise there was a positive relation between these variables $(r=0.64 ; P<0.001)$. There was no significant relation between these variables $60 \mathrm{~min}$ after exercise.
STATISTICAL ANALYSIS

Data are expressed as mean (SE). Two-way analysis of variance was used to test for disease or exercise effects. When such effects were confirmed, paired $t$ tests were used to compare pre and post exercise values within groups and unpaired $t$ tests to compare mean values between groups. General linear modelling procedures (SAS, SAS Institute, Cary, NC) were used to assess potential relations between independent and dependent variables of interest, and to compare the slopes of such relations between these two groups. $P$ values $<0.05$ were regarded as significant.

\section{Results}

High quality mean voltage neurograms were obtained in 15 healthy controls before exercise and in 14 after exercise, and both before and after exercise in 13 cardiomyopathy patients.

\section{BASELINE (PRE-EXERCISE) VALUES}

The characteristics and baseline values of the study groups are shown in tables 1 and 2. Age, weight, and body mass index were similar in the two groups. Muscle sympathetic nerve activity was higher in the cardiomyopathy group (45 (6) $v 21$ (2) bursts. $\mathrm{min}^{-1} ; \mathbf{P}=0.001$ ), in whom there was a corresponding increase in calf vascular resistance (55 (5) $v 31$ (3) units; $\mathrm{P}<0.0005$ ) (table 3 ). There was a significant positive correlation, before exercise, between muscle sympathetic nerve activity and resistance in the calf, the vascular bed distal to the recording electrode $(r=0.64 ; \mathrm{P}<0.001 ;$ fig 1$)$. 
Table 4 Exercise characteristics

\begin{tabular}{lllllll}
\hline Group & $n$ & $\begin{array}{l}\text { Duration } \\
(\mathrm{min})\end{array}$ & $\begin{array}{l}\text { Distance } \\
(\mathrm{km})\end{array}$ & $\begin{array}{l}\text { Target heart } \\
\text { rate }\left(\mathrm{min}^{-1}\right)\end{array}$ & $\begin{array}{l}\text { Achieved heart } \\
\text { rate }\left(\mathrm{min}^{-1}\right)\end{array}$ & $\begin{array}{l}\text { Ratio of achieved } \\
\text { target heart rate }(\%)\end{array}$ \\
\hline Controls & 17 & $45(0)$ & $5 \cdot 3(0 \cdot 2)$ & $157(2)$ & $145(3)$ & $92(2)$ \\
Dilated cardiomyopathy & 14 & $31(3)^{\star}$ & $2 \cdot 2(0 \cdot 3)^{\star}$ & $158(3)$ & $137(4)$ & $87(2)$ \\
\hline
\end{tabular}

Values are mean $(\mathrm{SEM}) .{ }^{\star} \mathrm{P}<0.001 v$ healthy controls.

\section{EXERCISE}

All healthy controls and four patients in the dilated cardiomyopathy group exercised for 45 min. Exercise was stopped in nine because of leg fatigue and in one because of dyspnoea. Achieved heart rate and the ratio of achieved to target heart rate were similar in the two groups (table 4).

\section{POST-EXERCISE VALUES}

Calf haemodynamics immediately after exercise There was marked calf hyperaemia immediately after exercise in both groups (fig 2). The magnitude of vasodilatation was greater in patients with left ventricular dysfunction when expressed in absolute resistance units $(P=$ 0.01 ), and similar in both groups when expressed as a proportion of initial pre-exercise resistance values, or when expressed as absolute or relative changes in calf vascular conductance.

After-effects of exercise on systemic haemodynamics and plasma noradrenaline and atrial natriuretic factor concentrations

In both groups there was systemic vasodilatation and diastolic hypotension an hour after exercise. Cardiac output was higher and heart rates more rapid after exercise. Total peripheral resistance decreased and total peripheral conductance increased (fig 3). The magnitude of these changes in healthy controls and dilated cardiomyopathy patients was similar (table 2).

In healthy controls both stroke volume and systolic blood pressure fell significantly below baseline values, whereas there was a $6 \%$ increase in stroke volume $(\mathrm{P}<0.005$ compared with the response in healthy controls; $\mathrm{F}=$ $12.61, P<0.001$ for this disease-exercise inter-
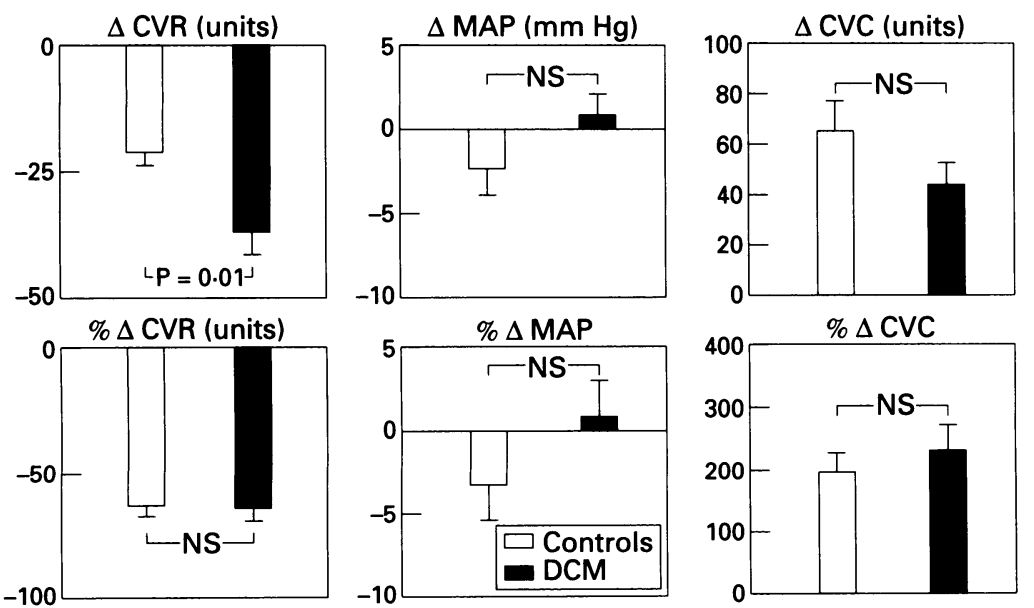

Figure 2 Absolute (upper panels) and relative (lower panels) changes in calf vascular resistance (CVR), mean arterial pressure (MAP), and calf vascular conductance (CVC) immediately after exercise compared with initial baseline values in healthy controls and patients with dilated cardiomyopathy (DCM). The magnitude of calf vasodilatation, expressed in absolute resistance units, was greater in those with dilated cardiomyopathy. action) (fig 3) and no significant systolic hypotension in the group with dilated cardiomyopathy $(\mathrm{F}=13.3 ; \mathrm{P}<0.001$ for this disease-exercise interaction) (table 2 ). There was a significant inverse relation between changes in total peripheral resistance and changes in stroke volume after exercise in healthy controls $(r=$ $-0.68, \mathrm{P}=0.002)$ and in patients with cardiomyopathy $(r=-0.75, \mathrm{P}=0.002)$ (fig 4 ). However, the slope of the regression line relating increases in stroke volume to reductions in total peripheral resistance was significantly steeper $(-1.03 v-0.40, P=0.03)$ in the dilated cardiomyopathy group, indicating a 2-3 fold greater effect on stroke volume of this exerciseinduced afterload reduction. Women with dilated cardiomyopathy displayed significantly greater increases in stroke volume $(+18(7) \% v$ $-1(4) \% ; P=0.04)$, and significantly greater decreases in total peripheral resistance $(-23$ (5) $\% v-8(3) \% ; P<0.02)$ than male patients.

Plasma noradrenaline concentrations tended to rise after exercise in healthy controls $(\mathbf{P}=$ 0.06 ), and tended to fall after exercise in those with dilated cardiomyopathy $(P=0 \cdot 15)$. Plasma atrial natriuretic factor was significantly lower after exercise in healthy controls only (table 2).

After-effects of exercise on muscle sympathetic nerve activity and calf haemodynamics

Sympathetic nerve activity was not affected by prior exercise in either group, whereas calf vascular resistance remained below baseline values $60 \mathrm{~min}$ after exercise (table 3 ). In contrast to the pre-exercise condition, there was no relation between peroneal muscle sympathetic

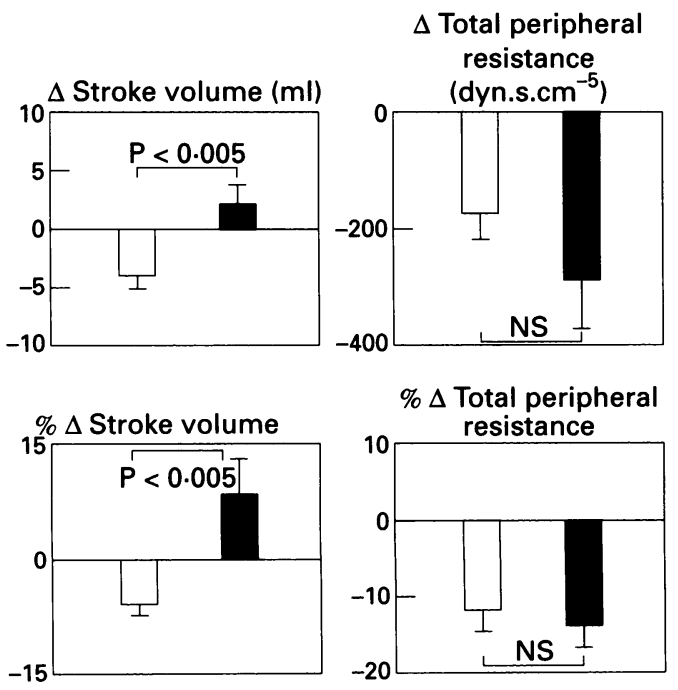

Figure 3 Absolute (upper panels) and relative (lower panels) changes in stroke volume and total peripheral panels) changes in stroke volume and total peripheral
resistance $60 \mathrm{~min}$ after exercise, as compared with baseline values before exercise, in healthy controls and patients with dilated cardiomyopathy (DCM). 
Figure 4 Regression lines relating changes in stroke volume, $60 \mathrm{~min}$ after exercise, from baseline, to corresponding changes in total peripheral resistance, in healthy controls and patients with dilated cardiomyopathy. The slope of this regression line was significantly steeper $(P=$ $0.03)$ in the group with impaired ventricular function.

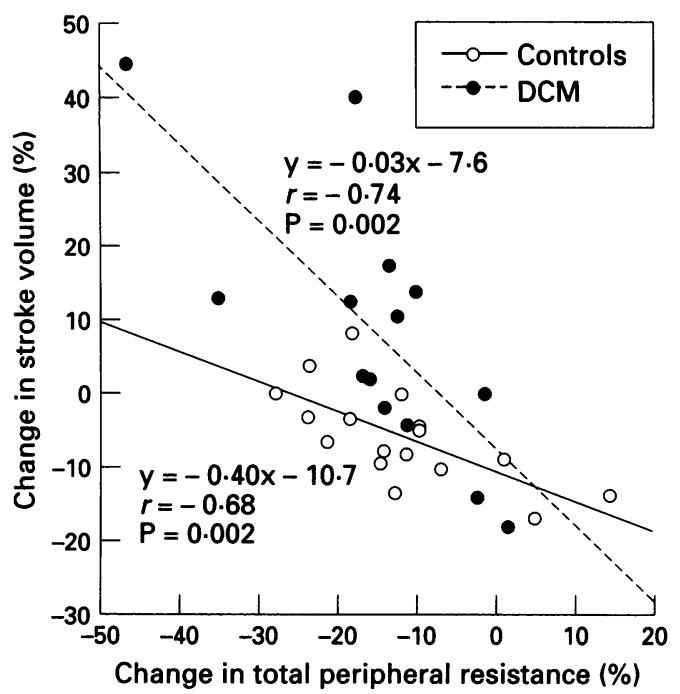

nerve activity and calf vascular resistance overall $(r=0.33$, NS; fig 1$)$ in either study group. Muscle sympathetic nerve activity $(P<0.01)$ and calf vascular resistance $(P=0.005)$ were significantly greater in the dilated cardiomyopathy group before and after exercise but the magnitude of calf vasodilatation, as represented by changes in conductance, was similar in the healthy controls and dilated cardiomyopathy patients. When expressed in absolute resistance units, the magnitude of vasodilaattion tended to be greater in those with dilated cardiomyopathy $(P=0.07)$.

Dissociation of after-effects of exercise from exercise workload

There were no significant correlations in the dilated cardiomyopathy group between exercise duration, exercise distance, and the product of exercise distance, and exercise heart rate (as three potential independent variables) and any of these sympathoneural or haemodynamic after-effects of exercise (as potential workload-dependent variables) with one exception: a positive correlation between exercise distance and heart rate after exercise $(r=$ $0.60 ; P<0.03)$. When the 14 cardiomyopathic patients were divided on the basis of exercise duration (group $1 \geqslant 35 \mathrm{~min} ; \mathrm{n}=7$; range 35-45 min, mean 41 (5) mins; group 2 $\leqslant 25 \mathrm{~min} ; \mathrm{n}=7$; range $15-25 \mathrm{~min}$; mean 20 (3) $\mathrm{min}$ ), there were no significant differences between these two groups in mean values for any of the cardiac (for example, stroke volume), calf, or systemic haemodynamic or any of the sympathoneural after-effects of exercise.

\section{Discussion}

AFTER-EFFECTS OF EXERCISE ON SYSTEMIC HAEMODYNAMICS

Post-exercise hypotension may occur by one of two mechanisms. In most young people with normal ventricular function resistance in both exercised and non-exercised vascular beds falls after exercise. ${ }^{47}$ The stimulus for this vasodilatation has not been established. ${ }^{427}{ }^{28}$ In contrast, in older hypertensives reductions in blood pressure after exercise are caused by profound and sustained decreases in cardiac output, with corresponding increases in total peripheral resistance. ${ }^{8}$ Before these experiments muscle sympathetic nerve activity and calf vascular resistance had not been studied in young patients with dilated cardiomyopathy, and the after-effects of symptomlimited submaximal exercise on their systemic haemodynamics and sympathetic outflow were unknown.

We documented a selective increase in resting baseline peroneal muscle sympathetic nerve activity and calf vascular resistance in these young patients with dilated cardiomyopathy. As in healthy controls calf and peripheral resistance fell after exercise; cardiac output remained above baseline values. Unlike healthy controls there was an increase in stroke volume after exercise in the group with dilated cardiomyopathy, and systolic blood pressure was maintained (fig 3). These contrasting after-effects of exercise on stroke volume cannot be explained on the basis of greater reflex sympathetic drive, to support left ventricular function, but resemble the differing haemodynamic responses of normal and failing hearts to acute pharmacological afterload reduction. ${ }^{29}$

\section{AFTER-EFFECTS OF EXERCISE ON MUSCLE} SYMPATHETIC NERVE ACTIVITY AND CALF HAEMODYNAMICS

\section{Sympathetic nerve activity}

In healthy controls spontaneous ${ }^{21}$ or drug induced $^{12} 2230$ reductions in diastolic blood pressure elicit substantial reflex increases in muscle sympathetic nerve activity. In the present series, comparable reductions in diastolic blood pressure and total peripheral resistance during recovery from exercise did not evoke reflex increases in nerve traffic or plasma noradrenaline concentrations in either group, indicating that there had been a sustained resetting of the arterial baroreflex control of central sympathetic outflow in both healthy controls and cardiomyopathic subjects. If the significant reduction in atrial natriuretic factor is indicative of decreased cardiac filling pressures the cardiopulmonary baroreflex control of sympathetic outflow may also have been reset by prior exercise.

\section{Calf haemodynamics}

Calf vascular resistance, both early and late after exercise, was higher in the group with dilated cardiomyopathy. Muscle sympathetic nerve burst frequency was twice that of healthy controls an hour after exercise, and non-neural mechanisms could also account for the greater residual vascular resistance in this group. ${ }^{31-33}$ However, even if present, these mechanisms did not blunt these patients' vasodilator response: exercise was followed by immediate and sustained reductions in calf vascular resistance in both groups, but the relative magnitude of calf vasodilatation (expressed as a proportion of initial pre-exercise values) in both the immediate and late recovery periods was similar. If expressed in absolute units, the magnitude of vasodilatation at both points in time was increased in the 
group with left ventricular dysfunction. Calf vasodilatation occurred in the absence of sympathetic withdrawal, whether assessed directly (muscle sympathetic burst frequency) or indirectly (plasma noradrenaline). In addition, the positive relation between peroneal muscle sympathetic nerve activity and calf vascular resistance, observed at rest, was uncoupled by this bout of exercise. Therefore, increased peroneal sympathetic nerve traffic to muscle in heart failure does not compromise the postexercise vasodilator response in the calf: rather, metabolic vasodilatation overrides this neurogenic vasoconstrictor stimulus. These observations may not reflect the after-effects of exercise on other haemodynamically important vascular beds, such as the kidney and splanchnic circulation, where the increased adrenergic drive of heart failure would not be balanced by the metabolic vasodilator response to exercise.

Our patients differ with respect to age, cause and duration of heart failure, and functional class from those in earlier reports describing impaired vasodilator responses to exercise..$^{34}$ Most were recruited within a year of their initial presentation, and had little or no peripheral oedema. Other groups report similar forearm blood flows during upper limb exercise in healthy controls and patients with heart failure but without significant oedema. ${ }^{35} 36$ We studied young subjects with dilated cardiomyopathy to exclude potential confounding influences of age or myocardial ischaemia on sympathoneural or haemodynamic responses to exercise. Although it might be argued that the after-effects of exercise we observed can not be generalised to patients with more severe heart failure, ours did not have benign disease: four subsequently deteriorated and required cardiac transplantation and one died suddenly.

\section{EXERCISE AS INTERVENTION}

Our purpose was not to study exercise performance itself but to examine after-effects that are sustained beyond the exercise-that is, viewing exercise as an intervention or perturbation and not as the object of quantitative study. The argument that relatively minor temporal differences in workload account for any observed differences between the two groups is implausible for several reasons. First, altered neurogenic vasoconstriction and reductions in blood pressure in subjects with normal ventricular function occur after much briefer periods of submaximal exercise- 10 min or less. ${ }^{27} 37$ Thirty minutes - that is, the average time that the cardiomyopathy group exercised-is sufficient to elicit this vasodepressor response. ${ }^{4527}$ Second, there was no relation in those with left ventricular dysfunction between exercise duration or workload and any of the systemic, cardiac, or calf haemodynamic or sympathoneural aftereffects of exercise. Thus, it is the performance of symptom-limited submaximal exercise itself, rather than any subtle "dose-effect" of exercise, that elicits these sustained aftereffects in patients with ventricular dysfunction.
Third, those between-group differences that did emerge could not be explained on the basis of between-subject variation in exercise duration or workload. Rather, the haemodynamic after-effects of symptom-limited exercise resemble those of pharmacological afterload reduction ${ }^{29}$ (for example, equivalent reductions in total peripheral resistance elicited two to threefold greater increases in stroke volume in those with ventricular dysfunction). This intervention seems to confer additional benefits upon those with left ventricular dysfunction: post-exercise hypotension and vasodilation did not cause (potentially detrimental ${ }^{11}$ ) reflex sympathetic activation, and exercise was followed by sustained reductions in calf vascular resistance.

These after-effects of a single bout of treadmill exercise provide further support for training, in properly screened and monitored patients, as a non-pharmacological adjunct to the management of chronic stable heart failure. The sympathoinhibitory effect of regular exercise in heart failure ${ }^{23}$ seems to be a function of training, rather than the cumulative response to sequential bouts of exercise.

We thank Beverley M Senn, RN, for her technical contributions to this project, and Dr Andrew Baines, Department of Clinical Biochemistry, The Toronto Hospital, for determining plasma noradrenaline concentrations.

This work was supported by the Heart and Stroke Foundation of Ontario (grants B1956 and T2326), the Pettit Fund of the University of Toronto, and the University of Toronto Centre for Cardiovascular Research. $\mathrm{KH}$ was sup ported by postgraduate fellowship funds from the Division of Cardiology and the Department of Medicine, University of Toronto and by the Medical Research Council of Canada. JSF was the recipient of a Clinician Scientist Award from the Ministry of Health of the Province of Ontario.

1 Sullivan MJ, Higginbotham MB, Cobb R. Exercise training in patients with severe left ventricular dysfunction: hemodynamic and metabolic effects. Circulation 1988;78: 506-15.

2 Coats AJS, Adamopoulos S, Radaelli A, McCance A, Meyer $T E$, Bernardi $\mathrm{L}$, et al. Controlled trial of physical training in chronic heart failure: exercise performance, hemodynamics, ventilation and autonomic function. Circulation 1992, 85:2119-31.

3 Coats AJS. Exercise rehabilitation in chronic heart failure. $\mathcal{F}$ Am Coll Cardiol 1993;22:172A-7A.

4 Coats AJS, Conway J, Isea JE, Pannarale G, Sleight P, Somers VK. Systemic and forearm vascular resistance changes after upright bicycle exercise in man. $f$ Physio (London) 1989;413:289-98.

5 Cleroux J, Kouame N, Nadeau A, Coulombe D, Lacourcière Y. After effects of exercise on regional and systemic hemodynamics in hypertension. Hypertension 1992;19. 183-91.

6 Hara K, Floras JS. Influence of naloxone on muscle sympathetic nerve activity, systemic and calf haemodynamics and ambulatory blood pressure after exercise in mild essential hypertension. $\mathcal{F}$ Hypertens 1995;13:447-61.

7 Hara K, Floras JS. Effects of naloxone on hemodynamics and sympathetic activity after exercise. $\mathcal{f}$ Appl Physio 1992;73:2028-35.

8 Hagberg JM, Montain SJ, Martin WH. Blood pressure and hemodynamic responses following exercise in older hypertensives. F Appl Physiol 1987;63:270-6.

9 Floras JS, Wesche J. Haemodynamic contributions to postexercise hypotension in young adults with hypertensio and rapid resting heart rates. F Human Hypertens 1992 6:265-9.

10 Ketelhut R, Losem CJ, Messerli FH. Depressed systolic and diastolic cardiac function after prolonged aerobic exercise in healthy subjects. Int $\mathcal{F}$ Sports Med 1992;13:293-7.

11 Floras JS. Clinical aspects of sympathetic activation and parasympathetic withdrawal in heart failure. $\mathcal{f} \mathrm{Am} \mathrm{Col}$ Cardiol. 1993;22:72A-84A.

12 Floras JS, Sinkey CA, Aylward PE, Seals DR, Thoren PN, Mark AL. Post-exercise hypotension and sympathoinhibition in borderline hypertensive men. Hypertension 1989;14:28-35.

13 Esler M, Jennings G, Korner P, Willett I, Dudley F, Hasking $\mathrm{G}$, et al. Assessment of human sympathetic activity from measurements of noradrenaline turnover. Hypertension 1988;11:3-20.

14 Thoren P, Floras JS, Hoffman P, Seals DR. Endorphins and exercise: physiological mechanisms and clinical implications. Med Sci Sports Exercise 1990;22:417-28. 
15 Leimbach WN, Wallin BG, Victor RG, Aylward PE, Sundlof G, Mark AL. Direct evidence from intraneura recordings for increased central sympathetic outflow in patients with heart failure. Circulation 1986;73:913-9.

16 Hasking GJ, Esler MD, Jennings GL, Burton D, Korner PI. Noradrenaline spillover to plasma in patients with congestive heart failure: evidence of increased overall and cardiorenal sympathetic nervous activity. Circulation 1986;73:615-21.

17 Manolio TA, Baughman KL, Rodeheffer R, Pearson TA, Bristow JD, Michels VV, et al. Prevalence and etiology of idiopathic dilated cardiomyopathy (Summary of a National Heart, Lung, and Blood Institute workshop) Am $\mathcal{F}$ Cardiol 1992;69:1458-66.

18 Feigenbaum $\mathrm{H}$. Echocardiographic evaluation of cardiac chambers. In: Feigenbaum $\mathrm{H}$, ed. Echocardiography. Philadelphia: Lea \& Febiger, 1972;119-87.

19 Devereux RB, Reichek N. Echocardiographic determination of left ventricular mass in man. Anatomic validation of the method. Circulation 1977;55:613-8.

20 Floras JS, Hara K. Sympathoneural and haemodynamic characteristics of young subjects with mild essential hypertension. F Hypertens 1993;11:647-55.

21 Sundlöf $G$, Wallin BG. Human muscle nerve sympathetic activity at rest: relationship to blood pressure and age. $\mathcal{F}$ Physiol (Lond) 1978;274:621-37.

22 Floras J. Sympathoinhibitory effects of atrial natriuretic factor in normal humans. Circulation 1990;81:1860-73.

23 Floras JS, Legault L, Morali GA, Hara K, Blendis LM Increased sympathetic outflow in cirrhosis and ascites: direct evidence from intraneural recordings. Ann Intern Med 1991;114:373-80.

24 Naughton MT, Rahman MA, Hara K, Floras JS, Bradley TD. Effect of continuous positive airway pressure on intrathoracic and left ventricular transmural pressures in patients with congestive heart failure. Circulation 1995; patients with

25 Davis JA, Convertino VA. A comparison of heart rate methods for predicting endurance training intensity. Med Sci Sports 1974:7:295-8.

26 Lautt WW. Resistance or conductance for expression of arterial vascular tone. Microvasc Res 1989;37:230-6.

27 Kenney MJ, Seals DR. Postexercise hypotension: Key features, mechanisms, and clinical significance. Hypertension 1993;22:653-64.

28 Piepoli M, Isea JE, Pannarale G, Adamopoulos S, Sleight $P$, Coats AJS. Load dependence of changes in forearm and peripheral vascular resistance after acute leg exercise in man. $₹$ Physiol 1994;478:357-62.

9 Parmley WW. Pathophysiology and current therapy of congestive heart failure. $\mathcal{F} \mathrm{Am}$ Coll Cardiol 1989;13:771-85.

30 Sanders JS, Ferguson DW. Diastolic pressure determines autonomic responses to pressure perturbation in humans. f Appl Physiol 1989;66:800-7.

31 Wroblewski H, Kastrup J, Norgaard T, Mortensen S-A, Haunso S. Evidence of increased microvascular resistance and arteriolar hyalinosis in skin in congestive heart failure secondary to idiopathic dilated cardiomyopathy. Am F Cardiol 1992;69:769-74.

32 Kubo SH, Rector TS, Bank AJ, Williams RE, Heifetz SM. Endothelium-dependent vasodilation is attenuated in patients with heart failure. Circulation 1991:84:1589-96.

33 Kiuchi K, Sato N, Shannon RP, Vatner DE, Morgan K, Vatner SF. Depressed $\beta$-adrenergic receptor- and endothelium-mediated vasodilation in conscious doos with heart failure. Circ Res 1993;73:1013-23.

34 Zelis R, Mason DT, Braunwald E. A comparison of peripheral resistance vessels in normal subjects and in patients with congestive heart failure. I Clin Invest 1968;47: w60-9.

35 Massie B, Conway M, Yonge R, Frostick S, Ledingham J, Sleight $\mathrm{P}$, et al. Skeletal muscle metabolism in patients with congestive heart failure: relative to clinical

36 Wiener DH, Fink PI, Maris J, Jones RA, Chance B, Wilson JF. Abnormal skeletal muscle bioenergetics during exerJF. Abnormal skeletal muscle bioenergetics during exercise in patients with heart failure: role of red

37 Bennett T, Wilcox RG, MacDonald IA. Post-exercise reduction of blood pressure in hypertensive men is not reduction of blood pressure in hypertensive men is not
due to acute impairment of baroreflex function. Clin Sci 1984;67:97-103. 